\section{An exploratory study of innovation strategies of the internet of things SMEs in South Korea}

\author{
Dong-Il Shin \\ Konkuk University, Seoul, South Korea
}

Innovation strategies of the internet

\begin{abstract}
Purpose - This study aims to suggest directions for innovation-driving paths for sustainable growth through an in-depth case analysis of a successful Internet of Things (IoT) in small- and medium-sized enterprise (SME) in South Korea. IoT is expected to play a significant role in the future industry 4.0 platform. Yet, little is known about how SMEs in the IoT industry (IoT-SMEs hereafter) pursue innovation in alignment with attributes inherent in the IoT.

Design/methodology/approach - This study addresses relatively unexplored key research questions on innovation strategies of IoT-SMEs. To do so, we employ an exploratory research methodology, along with an extensive review of the literature in the areas of the IoT, SMEs innovation and sustainable growth strategy. Specifically, we conduct intensive individual interviews to find IoT inherent innovation attributes and a case study to explore the process of linking these attributes to innovation-driving paths.

Findings - The analysis results reveal that there exist disruptive and open innovation attributes in the IoT industry that enable IoT-SMEs to enhance their structure and process related capabilities, to create business models for products and services and to collaborate with external parties in marketing to enter the market. We excavate practical insights into driving innovation based on Io T attributes and suggest enabling paths for pursuing innovation and entering overseas markets for IoT-SMEs.

Originality/value - This study investigates an underexplored significant area of research on the relationship between IoT attributes and innovation paths. The findings provide profound theoretical and practical implications. To the best of the author's knowledge, it is the first attempt to link disruptive and open IoT attributes to innovation paths of IoT-SMEs. The results provide directions for pursuing effective innovation in responding to the IoT market for sustainable growth.
\end{abstract}

Keywords Disruptive innovation, Open innovation, Value chain, Born global, IoT (Internet of things)

Paper type Research paper

\section{Introduction}

The Internet of Things (IoT), appeared in "Staff working paper on IoT" in 2008, is considered a part of the Future Internet (2009) in accordance with the European Union (EU) Framework Program[1]. Rapidly rising as a major industrial issue in the global trend, the IoT is foreseen to play a key role in not only industrial paradigm shift but future

(c) Dong-Il Shin. Published in the Asia Pacific Journal of Innovation and Entrepreneurship. Published by Emerald Publishing Limited. This article is published under the Creative Commons Attribution (CC BY 4.0) licence. Anyone may reproduce, distribute, translate and create derivative works of this article (for both commercial and non-commercial purposes), subject to full attribution to the original publication and authors. The full terms of this licence may be seen at http://creativecommons.org/ licences/by/4.0/legalcode

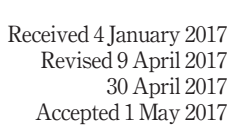

30 April 2017
Accepted 1 May 2017 
APJIE 11,2

management change and innovation. Observing this global trend, the Korean government has been actively supporting the IoT as well as Information and Communication Technologies (ICT) industry development through the Korea Information and Communication Technology (K-ICT) strategy crafted in 2015. In China, we find a case study of logistics and manufacturing small- and medium-sized enterprises (SMEs), urging them to apply knowledge management and transform to learning organizations, given that the IoT will dramatically change the landscape of logistics and manufacturing (Li \& Lu, 2010).

The global market is now being transformed into a platform-based competition for market dominance. Korean IoT-SMEs (SMEs in the IoT industry) are facing serious challenges as to making a strategic choice of whether to keep the status quo or transform for growth. The IoT connects various value chains, hence influencing one another (Kim \& Jung, 2013) and necessitating companies to cooperate. Therefore, it is critical to perform an indepth analysis of innovative IoT-SMEs, which can help identify the attributes inherent in the IoT and aid decision-making through the analysis of current situations and characteristics of companies.

In Korea, 99 per cent of manufacturing SMEs lack in implementing the network and information service-based Business Model (BM) required by the IoT industry (WIPO, 2015) [2]. In accordance with the 2013 Organization for Economic Cooperation and Development (OECD) data, the average survival rate of the Korean startup companies is 62 per cent in the first year of establishment and only 41 per cent in three years, the lowest among OECD member countries (Kauffman Foundation, 2015)[3]. Further, the average three-year survival rate in the entire industry is as low as 38.2 per cent in 2013, based on the statistics from the National Statistical Office (KOSTAT, 2015), raising a critical issue of sustainable survival as well as entrepreneurial startups. As a new trend of the IoT has foreseen a global market reorganization, a red light is on to Korean SMEs entering the global market (stat.kita.net). An open innovation policy study shows that successful SMEs in open innovation activities mainly utilized joint R\&D, networking for technology and market information gathering and technology consulting, and that in terms of cooperation types, bilateral cooperation is twice as much as multilateral cooperation (Kang et al., 2013). However, little research is finding that investigates IoT attributes and linking them to innovation paths for IoT-SMEs.

Therefore, this study intends to analyze the conceptual definition and attributes of the IoT industry and present policy implications through an exploratory study of Innovative Korean IoT-SMEs that have secured the growth base by linking these attributes. Further, as the advent of numerous emerging industries such as ICT, Big Data, artificial intelligence (AI) and Industry 4.0 urgently demands Korean SMEs today to develop effective strategic plans for innovation, this study aims to assess their limitations of looking at the existing IoT industry responding to the changes and provide a new perspective of driving innovation to IoT-SMEs.

\section{Review of the IoT research}

\subsection{Conceptual definition of the Io $T$}

The IoT is a concept and paradigm for thinking about things in an environment where various objects and subjects are connected by wire and wireless (IERC, 2013). The definition of the IoT varies by major organizations and corporations and by global standard organizations such as International Telecommunication Union (ITU), 3rd Generation Partnership Project, Institute of Electrical and Electronics Engineers, European Telecommunications Standard Institute have different definitions. These international organizations and the nations' major institutions reflect their own interests in defining the concept. For example, ITU interprets the IoT as an intelligent environment in which communication modules embedded in devices and objects are connected to a wired or wireless network, enabling information exchange and communication 
between people and objects and among objects (ITU-T, 2005). Recently we have observed is a trend toward standardization initiated by ITU-T IoT-GSI (ITU Telecommunication Standardization Sector IoT Global Standards Initiative), ITU-T JCA-IoT (ITU-T Joint Coordination Activity-IoT), ISO/IEC JTC 1 (a joint technical committee of the International Organization for Standardization and the International Electrotechnical Commission) and the Internet Engineering Task Force IoT. It is anticipated that the IoT era is coming as the things are getting miniaturized and smart with the advances in ICT-based technologies (Kim and Jung, 2013).

In the case of IoT-SMEs in Korea, many of them view the IoT as the advanced radiofrequency identification (RFID), Ubiquitous or ICT on the internet. The National Information Society Agency, 2013, anticipates that "in the future society, everything will be connected to the Internet through the mobile and communicate with one another". The IoT is the base technology and service of the hyper-connected society and a concept that has been extended to the IoE (Internet of Everything), starting from the existing Ubiquitous Sensor Network (USN) and the object intelligence communication Machine to Machine (M2M). Conceptually, these terms show similarity in terms of network connectivity and information sharing among things. The IoT can be defined as an object-space connected network servitized based on mutual intelligent relationship formation through cooperation, sensing, information processing and exchange and networking among objects without or with the least amount of human intervention.

\subsection{Characteristics of the Io $T$ research}

Korean companies' interest in the IoT was very low in 2013, staying at only 15 per cent in search by Google Trends (trends.google.com). In the study of IoT companies' overseas expansion strategies conducted in 2014, only half of the companies out of 40 companies interviewed expressed negative interest in the IoT industry (Deltatech Korea, 2014). However, by 2015 , this situation has changed drastically with the sharp rise of the interest in the IoT.

Early previous research on the IoT in Korea focused on technological change contexts (Nam, 2010; Kim et al., 2011). This research trend has advanced into a study on the value chain of the IoT (Moon, 2013; Kim et al., 2011) and then the research suggesting the direction of success in the IoT industry through a quantitative effect analysis (Jeong et al., 2013). There were studies of proposing the application sectors of the IoT and the expansion trend of target objects (Chun, 2014) and future IoT technology characteristics (Choi et al., 2014). Also, there were studies focusing on infrastructure for commercialization support such as security risks (Kang, 2014) and mitigation of prior regulations (Kwon et al., 2014).

Unlike those studies, a study focusing on the impact of the IoT industry (Kim and Lee, 2014) has emerged in 2014. Especially, the viewpoint that the IoT technology can change a company's position or the industry attractiveness has contributed to our present research by identifying the latent attributes of the IoT. Also, there were studies on major issues and directions of the IoT technology development (Lee et al., 2014) and specific development plans for improving utilization and satisfaction of IoT users (Lee et al., 2015). However, it has been difficult to find the research literature that suggests ways for Korean IoT-SMEs to approach and respond to the changes in the industrial paradigm caused by the IoT.

\subsection{Challenges to overcome market situations by utilizing the advantages of SMEs}

The advantages of SMEs are in their innovativeness, flexibility, and cooperation to respond quickly to changing environments (Carson et al., 1995; Gilmore et al., 2001; Hill, 2001; Laforet \& Tann, 2006; Simpson et al., 2006). However, there are also drawbacks such as a lack of resources and experts (Carson et al., 1995; Gilmore et al., 2001), unplanned and too simplistic 
nature (Carson \& Cromie, 1990; Fuller, 1994; Hogarth et al., 1996) and lack of marketing capability in effectively deploying innovative products in the marketplace (O'Dwyer et al., 2009; Hatonen \& Ruokonen 2010; Hausman, 2005). Thus, IoT-SMEs are required to establish a market entry strategy that maximizes their advantage to access highly competitive markets with a limited customer base because it is difficult to secure reliability in a rapidly evolving and uncertain market environment. Further, to compete against large companies with stable brands and international reputations in the market, SMEs should do so through innovation for survival (Salavou, 2004). Recognizing the limitations in the domestic market, it is natural for technology-based SMEs to pay attention to the innovation-generating capacity and the ability to create opportunities abroad (Harris, 1988; Keeble, 1997). Then, it is crucial to investigate how SMEs commercialize technology products in highly competitive environments (Acs \& Audretsch, 1990; Borg, 2009; Hatonen \& Ruokonen, 2010). Therefore, our study focuses on how to create synergy by linking the advantages of IoT-SMEs with innovation attributes of the IoT industry.

\section{Research design and methodology}

The purpose of this study is to analyze and present the findings of the critical elements and characteristics of Korean IoT-SMEs to enter and succeed in the overseas market through product and service innovation in the changing IoT environment. It is because many of the Korean IoT-SMEs have not yet realized the impact and importance of the IoT despite the advent of a new industrial paradigm called IoT. Moreover, as the Korean government has established a medium- to long-term support policy, it is necessary to investigate whether IoT-SMEs are actively responding to the IoT and making progress. In addition, if the overseas expansion is essential for Korean IoT-SMEs, it is necessary to analyze what their positions and status are and what their approaches and response strategies are.

To do so, we employ an exploratory research methodology such as individual interviews and case study, along with an extensive literature review. First, through the extensive literature review, we examine the scope of the IoT and innovation and growth potential of the IoT industry by analyzing innovation attributes, ecosystem and market structure. Second, through the intensive individual interviews of 40 Korean IoT-SMEs in 2014, we identify what their positions and status are in terms of their views, capabilities and preparation effort toward overseas market expansion, and what their approaches and response strategies are to cope with the changes in industry paradigm. Third, through an indepth case study of a successful Korean IoT-SME in 2016, we analyze the process of driving innovation to discover the critical elements and the alignment between IoT attributes and innovation paths for achieving sustainable growth in the IoT industry. Through the above analyses, we intend to better understand IoT innovation attributes and propose an effective innovation and growth strategies for IoT-SMEs in responding to changing environments.

The primary research question of this study is:

RQ1. What strategic choices do IoT-SMEs have for sustainable growth?

The basic premise behind this question is that the achievements of IoT-SMEs will be effective if they understand the attributes of innovation within the IoT industry and drive innovation according to their intended goal. Thus, we specifically propose the following research questions in a series:

$R Q 2$. What innovation attributes are inherent in the IoT industry?

$R Q 3$. What types of innovation-driving path do IoT-SMEs choose for their survival and growth? 
RQ4. What patterns exist between IoT innovation attributes and innovation-driving paths of IoT-SMEs for achieving their intended goals?

\section{Characteristics and innovation attributes of the IoT industry}

\subsection{Characteristics of the Io Tindustry}

The common concept of the IoT industry can be summarized as minimizing human intervention, connectivity and networking. Unlike the existing industries, the IoT industry exhibits such characteristics as universality, infinite scalability and continuous innovativeness, given its base on data. In accordance with IEEE (2015), its scope includes 16 fields (stakeholders) in eight markets, whereas Beecham Research, CISCO (2014) and Global Sensor Networks, Tata Consultancy Service, KISA (2012) have different scope by classifying business categories such as IoT components differently.

The keen interest in the IoT market is because it enables the existing ICT ecosystem to expand and secure long-term growth potential of the industry. In accordance with the Korea Internet Promotion Agency (2012) and OVUM (2011), the value chain of the IoT consists of semiconductor, chip, module, device, platform, network and service, while Gartner (2013) classifies it into horizontal technology market and the vertical industrial sector market and in the horizontal technology market, semiconductor, software and service are considered the three most important platform technologies understood as IoT value chain-based technologies. The research on the IoT-related value chain and market component (Kim \& Jung, 2013) and prioritization of application areas in the value chain (Moon, 2013) provide good implications to IoT-SMEs in making strategic decisions.

The IoT-related business ecosystems are rapidly evolving. The number of the internet startups increased from 792 in March 2015 to 3,365 in March 2017 (https://angel.co/internetof-things). In addition to industrial manufacturers such as GE, Siemens, Bosch and Philips, large companies in the ICT field such as Cisco, Intel, Apple and Samsung are participating, and M\&As in IoT-related fields are also increasing (www.prweb.com/releases/2015/01/ prweb12424187.htm). Further, the participation of companies in Asian-Pacific region is increasing in the US- and Europe-based IoT ecosystem such as Withings, Sigfox and Netatmo.

The IoT ecosystem in Korea is composed of government public institutions, specialized technology transfer institutions, domestic product and service companies and overseas brand companies, with platform and cloud service at the center (see Figure 1). In the case of government public institutions, it is linked to specialized technology transfer institutions mainly by application products and services, and relates to overseas brand companies through a network. In the case of domestic product and service companies, they are connected to solution delivery business and system integration business with specialized technology transfer institutions, and they are also connected to overseas brand companies with device products. These are linked to the value chain and integrated into the platform and delivered as a cloud service.

Considering the future market in 2022, the application market is the largest at US $\$ 1.194 \mathrm{tn}$, whereas the growth rate of the solution providers and system integrators is much higher than that of the application and services, with its annual average growth rate of 66.1 per cent in 2013-2022 (STRACORP, 2013). In this regard, it is necessary for Korean IoTSMEs and venture companies to carefully examine the necessity of forming a partnership by precisely grasping their own capabilities considering the position and dynamics of the global leading companies in the IoT Ecosystem. Also, the choice of a value chain to understand the link with the surrounding ecosystem is very important. Thus, our study 


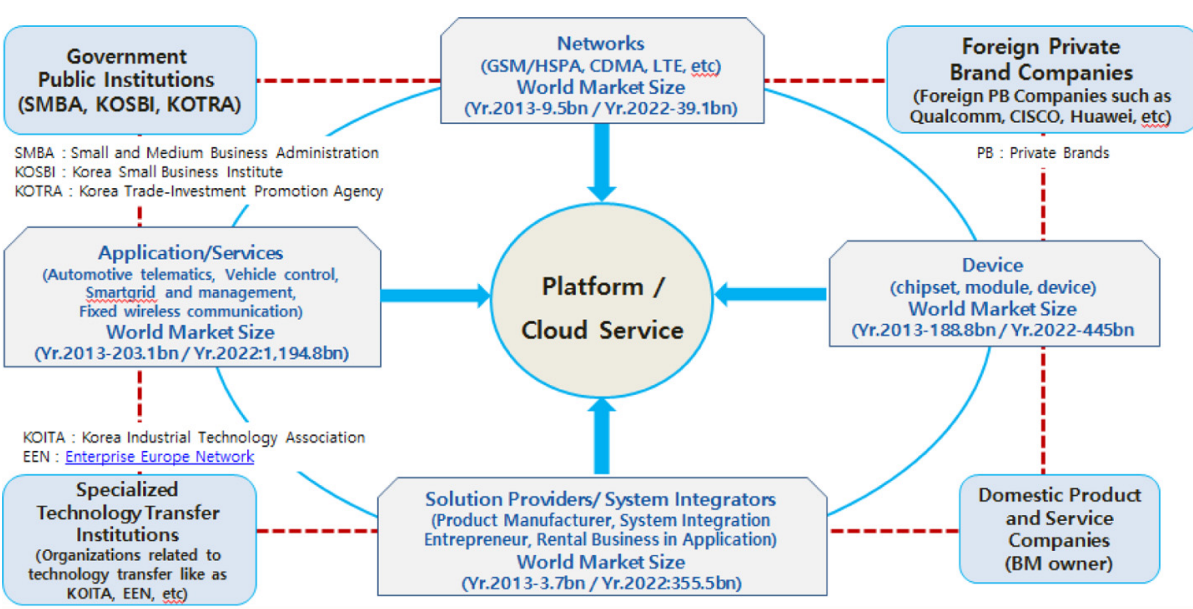

Figure 1.

IoT Eco-system in Korea

Source: STRACORP (2013), KOITA (2014), CSD Consulting reorganization

proposes an effective pathway to localization needed for developing a global market entry strategy.

\subsection{Innovation attributes of the Io T industry}

In the IoT industry, there are two inherent innovation attributes: disruptive innovation attributes (Ma and Zhang, 2011; Frost \& Sullivan, 2014; Telecom Asia Vision, 2016; Beth, 2016) and open innovation attributes (Boon \& Looi, 2015; AnupSahoo, 2016; An \& Chun, 2015; Kang et al., 2014). The National Information Commission (NIC: National Intelligence Council) in the USA selected the IoT as one of the "Disruptive Civil Technology" that will affect national competitiveness by 2025, and Korea's Ministry of Science, ICT and Future Planning has supported the IoT industrial ecosystem by inducing open partnership of winwin cooperation through an open platform. The US Open Census (OpenSensors.io) has demonstrated the potential of data sharing analysis and service innovation by analyzing the causes to a problem based on real-time accumulated data and suggesting an approach to problem-solving (Oxford Flood Network). The innovations that are potentially inherent in the IoT industry start from the infinite possibilities of "data". This is also related to the connection properties of the IoT.

4.2.1 Disruptive innovation attribute. Unlike sustaining technology that values the performance improvement of existing products demanded by demanding customers, disruptive technology makes potential consumers easier to use and provides relatively simple low-end products. Disruptive technology is an innovation strategy that can never be achieved without lowering the cost of parts, reducing manufacturing costs and shortening the development time. This attribute is inherent in the IoT industry, and thus, various devices such as wearable devices, drones, smart home, health care and smart city are emerging from various sensors and semiconductor chips. It helps to predict the arrival of industry growth and innovation business. To successfully pursue innovation strategies in such a situation, it is necessary to utilize Resources, Processes and Values (RPV) theory (Christensen et al., 2004). It is because companies can succeed by using resources, processes 
and opportunities that meet their values. In addition, it is necessary to understand and cooperate with the resources and value chain among the IoT companies.

D’Aveni (1994) proposed a creative market disruption model as an innovation strategy for companies under hypercompetition and suggested a vision, capability and tactics for disruption. In addition, Prahalad and Mashelkar (2010) pointed out disrupting business models, modifying organizational capabilities and creating or sourcing new capabilities as critical elements that enable a breakthrough innovation.

4.2.2 Open innovation attributes. In the IoT industry whose infrastructure consists of Innovation strategies of the internet connectivity characteristics of networking, dynamics within the value chain and the formation of ecosystems, there is an inherent open innovation attributes (AnupSahoo, 2016). At The Association of Southeast Asian Nations (ASEAN) IVO Forum 2015 of National Institute of Information and Communication Technology, Boon and Looi (2015) suggested the adoption of open platforms for IoT solution and application development that cooperate through "IoT Innovation Platform" and anticipated that the platform would accelerate industry growth. In addition, they expected that the cooperation of the IoT based on the open innovation platform would contribute to the creation of the ASEAN innovation ecosystem and market value. The Journal of Information and Communication by the Korea Information Society Agency mentioned the need for a software-centric infrastructure that supports open innovation in the hyperconnected society through the "hyperconnected social infrastructure that accepts open innovation".

Kang et al. (2014) predicted that efficient sharing of resources would be achieved through advanced wired and wireless networking in an open software-centric virtualized cloud. The open innovation trend supports the inclusion of more networks and the harmonious expansion of the ecosystem by constructing an open platform for the IoT. It also promotes open partnerships to enable radical innovation. It is important to note that the IoT already has the property to accommodate the existing innovation theory. The IoT, the value chain of which consists of such elements as chips, sensors, modules, devices, equipment, networks, communications and services, requires cooperation and technical convergence within the value chain and connectivity and communication with external ecosystems. These attributes connect a smart home to the household appliance industry, smart farm to the agriculture, livestock, forestry and fishery industries and smart car to the automobile industry. This implies the importance of the cooperation strategy for companies to survive and achieve sustainable growth in the IoT industry.

\subsection{The capabilities of IoT-SMEs for linking Io T attributes with innovation-driving paths}

4.3.1 Network capability and positioning-based response capability. To properly select and utilize an innovation attribute inherent in the Io T, companies need to respond appropriately and secure necessary capabilities, that is, networking capability - the fundamental attribute of the IoT-and ecosystem adaptation capability. Companies can craft a step-by-step response strategy, such as incremental innovation, but what is required in a changing environment of new industrial paradigm, is rapid and precise responses. In the study of SMEs in Russia, which has undergone very rapid changes in recent decades, Kyllikki et al. (2014) pointed out SMEs' need to adapt to the rapidly changing environment and secure networking capability as well as inner capability. These factors can be similarly applied in industrial environments where the IoT is applied.

In addition to networking capability, it is necessary to understand the surrounding ecosystem and to decide which positioning-based response to take. Kapoor and Adner (2015) argued that the success of new technology depends on the degree of completeness of the ecosystem to which the technology will be applied. An example of establishing technology 
ecosystem is found in sales hybrid cars and electric cars. They appeared at similar times, but hybrid cars accounted for 84 per cent (1.65MM) of total sales volume (1.95MM) of environment-friendly cars, while electric vehicles accounted for only 8.9 per cent (Korea Automotive Industry Research Institute. 2014).

4.3.2 Internationalization capability. Internationalization capability is a capability needed for survival and adaptation that SMEs can consider and choose to overcome the limitation in domestic market size. Esteve-Pérez et al. (2007), who analyzed small and medium manufacturers in Spain from 1990 to 2002, suggest that export-oriented SMEs are more likely to survive than SMEs focusing on the domestic market. Similar results are found in Bernard and Sjoholm (2003) and Melitz (2003).

There are also findings that born global companies can make profits through the learning effects from exploring international market opportunities and capitalization (Autio et al., 2000). Lee et al. (2012), in their study of 1,612 Korean venture SMEs, discovered that the technology asset does not have a direct effect on survival, but $R \& D$ alliances do, and that internationalization provides survival opportunities. Thus, to increase survival rate, alliances with external resources, which give more opportunities to contact with external resources, are more important than internal resources, based on resource-based view.

\subsection{Innovation-driving paths of IoT-SMES}

4.4.1 Characteristics of innovation-driving paths of IoT-SMEs. Innovation originating from the Latin "inovare" that means "creating something new" is considered a way of changing opportunities into new ideas and making them widely used. The types of innovation have been introduced over include product and process innovation, radical and incremental innovation, system innovation, component innovation, technology driven and market driven innovation, closed and open innovation (Hoffman et al., 1998). In the Oslo manual, the types of innovation refer to product, process, organization and marketing innovation (OECD, 2005). However, it is difficult to find studies related to innovation models specific to SMEs, and most studies have focused mainly on entrepreneurial and structural characteristics (Hoffman et al., 1998). According to Laursen and Salter (2004), there is no evidence that large firms are more likely to innovate than SMEs in an entirely new type of innovation, and these results indicate that SMEs also have the capacity to make innovation, especially radical innovation.

Unlike those studies arguing that firm size does not affect innovation activities (Soete, 1979; Freeman, 1982; Rothwell \& Zegveld, 1982), some studies assert that technology and demand characteristics are more important to firm innovation (Pavitt, 1984; Pavitt et al., 1987). Although the findings show that there is no correlation between firm size and technology innovation and that SMEs can adapt to changing environments more rapidly through their flexibility, they need to collaborate with other companies due to their lack of capabilities dealing with total innovation (Edwards et al., 2005). SMEs are in the important position in the country and at the center of the policy that drives economic development as the backbone of regional industries (Jones \& Tilley, 2003).

4.4.2 The innovation-driving paths type of IoT-SMEs

4.4.2.1 Step-by-step growth. The early model of innovation explains innovation activities as those of several functional activities performed step-by-step from a simple and psychological form (Tidd et al, 2015). Thus, innovation is understood as a process by which the desired form of innovation is made in the way you think. Rothwell (1992) suggested that historical perceptions of innovation attribute evolve from a single-line model (characteristics in the 1960s) to a complex interaction model. He viewed innovation as a multi-player 
through the concept of " 5 th generation innovation" and mentioned that this activity becomes easier as IT development improves internal and external integration level.

Scott and Bruce (1987) mentioned the evolution through survival and growth as the type of innovation in SMEs and classified the problems and growth patterns of SMEs from a perspective of survival and step-by-step growth evolution. He found that SMEs exhibit differences in size and growth capability and have such characteristics as independence of behaviors, differences in organizational structure and diversity of management styles. In addition, pointing out that the same problem is usually experienced at the growth stage, consisting of "Existence", "Survival", "Success", "Growth or Take-off" and "Resource Maturity" and that not all companies are going through this entire process. Then they suggested how SMEs have overcome the crisis of survival and need cooperation in the transition from growth to maturity.

This type of step-by-step growth is consistent with incremental innovation and step-bystep internationalization theory and can be defined as self-evolving type. The representative innovation activities include independent R\&D, product technology and process innovation, core competencies and RPV-based innovation activities.

4.4.2.2 Open innovation. The type of open innovation-based collaboration in SMEs can be classified into outside-in (e.g. insourcing, collaborative research, venture investment, technology procurement, research contract, long-term support, joint venture, M\&A), insideout (e.g. technology asset sales, spin-off, project result release) and coupled collaboration (Enkel et al., 2009; Bok, 2006; Kim et al., 2008). Gemunden and Heydebreck (1995) argue that the greater the firm size, the greater the level of external cooperation, especially the collaboration with universities and research institutes.

Parkhe (1993) also analyzed empirically that firm size shows a significant correlation with the degree of technological sophistication and intent of joint research and development. Egelhoff and Haklisch (1994) argued that the smaller the firm size, the stronger the tendency to avoid open innovation and collaborative research. Further their empirical study found that product development alliances increase as companies move from introduction to growth to maturity in industry life cycle.

Prior research showed that firm collaboration affects their performance and that the degree of collaboration differs by the stages of firm growth. This type of driving innovation can be defined as a type of alliance-based collaboration, and it can expand the capabilities that companies have in terms of technology development through joint R\&D activities or market entry and enhance effectiveness.

4.4.2.3 Mixed type: step-by-step growth combined with open innovation. Technology cooperation of SMEs in terms of the method, partner, motivation and the change in content is considered important, as they can influence the technical performance of a company (Jeong \& Bae, 1997). Hiromi Saito (2010) investigated 10,731 companies in Japan and discovered their mixed R\&D characteristics which is considered absorptive capacity and defined as "mixed type". Because mixed R\&D requires innovation activities based on platforms and networks, the capability that a company has must reach a certain level required for cooperation. The core of this mixed model lies in collaboration with external resources based on its own capabilities rather than relying solely on outsourcing.

4.4.2.4 Global partnership. Kanter (1994) presented various partner relationships in terms of strength and closeness of cooperation. This study is important from a value chain partnership perspective, as the concept extends to value chains in other industries beyond that in the same industry. Thus, SMEs needs to have such perspective when they are trying to establish global partnerships.

\section{Innovation strategies of the internet}


APJIE 11,2

180

For SMEs, it is difficult to enter the overseas market even though it is required. Although the government supports global partnerships to develop overseas markets, the reality is that SMEs are passive, as they cannot find the market or lack in capabilities or the business model is not prepared for partnership. Previous research on overseas expansion has focused on venture firms' entry into overseas markets, types of entry and achievements (Coviello \& McAuley, 1999; Fillis, 2001; Rialp et al., 2005; Zahra, 2005; Zahra \& George, 2002). In the previous studies on the international management activities of venture companies, venture business startups have focused on the individual dimension of the management (Burgel \& Murray, 2000; Oviatt \& McDougall, 1995) or domestic industry characteristics and local market characteristics, as key drivers (Femhaber et al., 2007; Karagozoglu \& Lindell, 1998; Smith et al., 2000). These studies emphasized that the growth of the domestic market is stagnant, the level of competition is stronger, the market growth rate is faster in local countries and the internationalization of venture companies is more advanced when the competition level is low. Other studies based on resource-based view have focused on the resources and capabilities of venture firms (Knight \& Cavusgil, 2005; Zahra et al., 2003) and relational capability or social capital to complement the inherent limitations of venture firms (Yli-Renko et al., 2002; Zain \& Ng, 2006).

\section{Exploratory study}

\subsection{Interview results of Korean Io T-SMEs}

To clarify more clearly the situation of IoT-SMEs in Korea, we conducted concurrently the field visits and telephone interviews of 40 companies during September 2014. The content of the individual interviews focused on the awareness and response situation of domestic IoT businesses, the necessity and timing of overseas expansion (Table I).

The outcome showed sharp contrast, having 20 companies with negative perceptions and the other 20 companies with positive perceptions (14 companies expressing strong interest in overseas expansion and 6 companies expressing that they would wait and see). Only 15 companies (37.5 per cent) expressed confidence in BM they developed and 31 companies showed the interest in partnering or searching for ones to enter the global market.

The more firms that have failed in R\&D investment and business such as RFID and USN, the more negative the tendency to enter the overseas market is. Although those companies that have been active in overseas expansion have modified their positions in the value chain or have already designed or commercialized specific BMs, most companies have not prepared for BM concept yet. Those companies that are considering overseas expansion, expect to receive the government support of education and consulting so that they can creatively develop a BM.

The interviews show that the current situation in the IoT industry is very unclear to the IoT-SMEs. As the companies have different levels of capabilities in different situations, a new approach is required, different from the existing R\&D and export support policies. By

Table I.

Participating IoTSMEs in interview by sales volume

\begin{tabular}{lccccccc}
\hline Classification & \multicolumn{7}{c}{ Interviewed firms (by sales) } \\
\hline Sales (Unit: 100m KRW) & $\sim 10$ & $10 \sim 30$ & $30 \sim 50$ & $50 \sim 100$ & $100 \sim 500$ & $500 \sim 1000$ & $1,000 \sim$ \\
Number of firms & 5 & 4 & 2 & 3 & 9 & 5 & 12
\end{tabular}

Notes: In accordance with the Enforcement Decree of the Framework Act on Small and Medium Enterprises Article 3, among the interviewed companies, there were 30 firms with sales of less than $150 \mathrm{bn}$ KRW in IoT industry 
comparing and analyzing the status and competence level of these interview companies, we found that Korean IoT-SMEs need to understand innovation attributes of the IoT, select the market, product and the innovation-driving path and plan and execute innovation and internationalization.

Innovation
strategies of
the internet

181

5.2 Case study of an innovative Korean Io T-SME

We conducted a case study for Nuri Telecom, a systems software developer and supplier for 24 years since its start in 1992 whose name was changed to Nuri Telecom in 2000. As a Korean IoT-SME with sales of 30bn KRW and a patent in the field of remote meter reading, it has developed its own solution and made a growth engine. It is one of the representative Io T companies in Korea that did not stay as a single product manufacturer in the domestic market and continues to grow and innovate as a set maker and solution service provider. We will examine the response strategy of Nuri Telecom from a viewpoint of IoT attributes, which overcame the limitations in the domestic market through overseas market expansion by forming global partnerships and has strived for development of a new BM and cooperation in technology development to compete in the global market.

5.2.1 Internationalization: developing overseas market based on own R\&D capability. Nuri Telecom, which originated from the software in the early days of its founding, has developed hardware through the development period of seven years, pioneered the remote meter reading device market in Korea, developed CDMA and delivered it to KEPCO. Since then, they have focused on program development and became a set maker of Full Set manufacturing, succeeding in developing a product package. Now they are facing more competition (KT, LG U+, etc.) in the field. After changing to "Nuri Telecom Co., Ltd." and aiming at overseas market within one year, it became the top export company in the domestic remote meter reading device market. Although it continues to do the business of RFID that is the foundation of M2M IoT and has the capability to build the equipment and solution modem from the bottom to the top, now it is more of a service company than the equipment and solution company with the proportion of services (70 per cent) and solutions (30 per cent).

Nuri Telecom has the top-level technological capability of achieving the reading success rate of 99.8 per cent in the test for its finished product in Sweden. The first example of M2M that it pursued is a remote meter reading device, which is an IoT solution product. The network equipment is constructed as a mesh network by mesh method, so that it can establish a flexible network that can be restored even if any one of them is damaged. In the AMI (Smart Grid) product line, which is an area of automatic meter reading device, exports accounted for more than 50 per cent of total exports in 2015. As a product standard, AMI's share of exports grew from 41.1 per cent in 2014 to 65.6 per cent in 2015, and exports accounted for 69.3 per cent in the third quarter. In terms of products, AMI exports accounted for 18.7 per cent in 2014 and increased to 30.7 per cent in 2015, and the proportion of exports of RFID was increased in 2016.

5.2.2 Open innovation: cooperation with external parties and responses. In the global market, Nuri Telecom is securing its competitiveness by partnering with large companies to deal with global competitors. In addition, the company could achieve sustained survival and growth with its strategy of securing price competitiveness and self-maintenance capabilities as well as various deployment cases. Currently, in the USA, large companies such as Itron and Silver Spring Networks are present with their installation of one million households, and there are more than 30 larger competitors. In contrast, Nuri Telecom covers a range from 100,000 to 300,000 households, but they have low-cost systems and price competitiveness. Thus, global companies also recognize Nuri Telecom as a competitor. Even 
APJIE 11,2

in the more competitive heavy electric power sector, in the case of power generation, entering the consortium is the only way and the forces are not yet formed. Therefore, they need to participate in the market to be involved in the standard so that it can be within the entry barriers.

Symbol Technology, Alien, Matrics, Philips and TI are among the world's leading suppliers of RFID systems. In November 2004, Nuri Telecom was selected as a partner for Motorola (M\&A of Symbol Technology) and Premier Solution and has actively conducted RFID and automatic recognition business. The survival strategy that Nuri Telecom considers and prepares in the IoT era is the response to the standard and cooperation. Europe requires to specify the standard and asks to back up its standard later if it is not there yet. Nuri Telecom follows the M2M international standard, and it is common for overseas customers to make a request first.

All electricity and service networks in Korea are tailored because electricity is post-paid. In contrast, in overseas, a prepayment system is common, and there are many places that use the charge system and the electricity is cut off when the charge is finished. Therefore, it is important to check the remaining charge with an electric shut-off meter or a charging system. Nuri Telecom is currently cooperating with 13 major companies. The disadvantage of collaborating with these partners is that Nuri Telecom has to conform to their specific standards. Therefore, Nuri Telecom has always been developed and distributes products considering these standards because it is necessary to change these standards when entering the overseas market. If it does not meet the standards, Nuri Telecom will always be asked by buyers to explain the reasons and future strategies. At present, Nuri Telecom has its own customization capability to meet overseas standards and certification.

5.2.3 Disruptive innovation: BM development and response. It is the BM that Nuri Telecom is prepared for the global market. In Korea, it is common to receive a new concept, but overseas markets are being asked to present a BM. It is very important to respond quickly to technical standards or BM depending on the country, and Nuri Telecom has strong competitiveness in this respect. In the process of doing business, Nuri Telecom is aware of the need for a new BM of the rich or poor countries, and it is currently expanding its business in developing countries. In the places where the cooperative relationship exists among the global consultative body, there are large corporations that maintain cooperative relations in developing data bases (DBs) and chips. There are also companies in competitive relations. The future farming is moving toward smart farm. In this area, Japan has M2M capability. Nuri Telecom is preparing for the technology roadmap and continue to refine it over the next three years.

Technology has been developed through continuous modification and chip development is a great know how. These technologies are difficult to disclose and do not yet have to be shared or released. For example, in the case of a chip, it is a perfect solution when it is required to make a correction. This takes a lot of time and requires combining various points of view. Large companies that collaborate demand sharing of these technologies, but in that case, it is difficult to keep the business together. To strengthen its own capabilities, it provides strong compensation for developing patents inside to secure them, and the R\&D research team conducts company $R \& D$ by participating in national R\&D. Solution development is also a result of obtaining the national R\&D order. Thus, it has a commercialization process in technology development and operates a separate team for this.

5.2.4 Moving from self-evolving type to the mixed type in driving innovation: response from the technology development perspective. Among the total 56 patents, registered based on applicants, it holds eight registered patents related to telecommunication and possesses strong competence in terms of technology. It usually carries out independent $R \& D$, but it 
also conducts joint R\&D although it is rare. However, as the need for security technology development is raised through recent interviews, it judges that there is an increasing need to cooperate with security technology companies to develop technologies to replace existing foreign solutions. This judgment is based on recognition that past R\&D alone is difficult to survive in the global market competition, and shows that outside-in innovation is required through cooperation with external parties.

In the case of RFID, USN and IoT, the technology required in terms of internal capabilities is security technology. This technology is used by purchasing the foreign solution, and thus the cooperation is urgently needed to secure it.

Nuri Telecom considers the need for an energy storage system (ESS) system technology that saves energy by using big data. It ponders on how to provide a competitive solution and service to energy management solution (EMS) in the electricity, water and gas energy management. Although there are overseas branches, it is difficult to publicize and there are many strong competitors. Thus, it is necessary to make a pilot. However, it is also a big problem that large companies are not interested in.

\subsection{The implication}

Through the above literature review and case analysis, we examined various attributes such as connectivity, universality and scalability of the IoT, and the disruptive and open innovation attributes. It has also been found that there are characteristics that cause radical changes in the products and organizations, and changes in manufacturing processes. The case study revealed that the innovation-driving and growth paths of the successful IoT-SME in Korea has an effective alignment between the IoT innovation attributes and the innovation-driving paths.

The first stage of the innovation-driving path is the step-by-step growth through selfevolution. As a representative of RFID M2M, considered a predecessor of the IoT, it shows a viable early stage innovation path to secure its own R\&D capability and grow as a set maker in the domestic market. The second stage of the path is the aligned cooperative growth that embraces open innovation and utilizes strategic partnerships during internationalization. In recognition of the limited demand in the domestic market, it has continued to survive and grow through partnerships with large companies in terms of open innovation to secure a competitive advantage in the global market while aiming for internationalization. In this process, the case company has established strategies for securing demand-oriented standards, by recognizing that ecosystem survival strategies in the IoT industry require the response to the standard and cooperation and, of course, it is also an important factor that enhances its own capacity for internationalization. The third stage is the preparation of the BM as a disruptive innovation for sustainable growth in the global market. This gives a new market value to existing products for smart consumers, smart cities and smart factories, and it is a new viewpoint in the market but not a new technology. The fourth stage is the shift in technology innovation perspective. The case company is moving from the initial self-evolution type through the medium-term cooperation to the mixed type of driving innovation. It has secured the IoT related patents, preferring independent $\mathrm{R} \& \mathrm{D}$, but recently it has been working on joint $\mathrm{R} \& \mathrm{D}$, recognizing the necessity to cooperate with external parties as its business scope expands.

In the above case, the innovation path, which the Korea's IoT-SME has followed while maintaining their survival and growth for 24 years after changing their mission, was achieved by selecting strategies and types appropriate to the situation. This provides many implications for companies in the field. The specific path that played a major role in securing 
the basis for sustainable growth can be summarized as the self-evolving stage followed by an aligned cooperative growth stage and then by the mixed stage.

\subsection{Discussion of the innovation-driving path}

5.4.1 The self-evolution path type: self-empowerment. This study suggested the paths of driving innovation to SMEs which are trying to enter into the IoT industry so that they can effectively prepare for and respond to environmental changes. It is since early startups, especially those are not ready for a proper BM or overseas expansion, might be wondering what innovation-driving path they need to choose and why. In such case, it is imperative for SMEs to go back to the basics of following the step-by-step innovation for self-evolution, preparing for BM and strengthening capabilities for overseas market entry. It is desired for the government to provide SMEs with methods and tools for analyzing Big Data and providing information on IoT development environment of and market and technology trends to aid their decision making and enhance their capabilities.

5.4.2 The aligned cooperative path type: strategic partnerships during internationalization. The aligned cooperative path type, whether linked with disruptive or open innovation attributes, is a strategy that can be considered for companies which are trying to leap up by expanding capabilities through proprietary technology competency or innovative BM. Such companies need to adapt their capabilities to the global market goals and to seek cooperation with related companies in the value chain. The government also needs to provide a strategic guidance to IoT-SMEs so that they can derive a new BM to maximize the possibility of success in the market by matching the companies with excellent ideas and those with manufacturing competencies in the enterprise pool.

Alliance and cooperation within the value chain and the consideration of external ecosystems enable companies to develop a global market-oriented BM based on disruptive innovation. Those companies can reduce the costs of parts and manufacturing and shorten the development time which cannot be achieved by "sustaining technology". They can provide a simple product called "low-cost entry model" to low-end market customers. If they understand the IoT innovation attributes well, they can achieve service innovation and business innovation by providing the value that customers want.

5.4.3 The mixed innovation-driving path type: securing sustainable growth base. The mixed innovation-driving path type, combining self-evolution path and aligned cooperative path, can be considered in large companies or companies with various businesses. In this case, if the company collaborates with external parties based on its core competencies, its performance can be significant and is closely linked to the characteristics of open innovation. Since this path plays a key role in the creation of the IoT ecosystem, it is an appropriate strategic choice to those competent companies such as hidden champions and leading companies in the value chain.

How companies respond to the future will influence the Korean IoT-SME industry in developing new competencies for sustainable growth. For this, it is necessary to establish a global partnership with network, equipment and solution groups using the platform focusing on the IoT value chain and to advance in the market based on this mixed innovation driving path. Cooperation with companies within and across the Io $\mathrm{T}$ value chain is useful for BM discovery, and most of all, for sharing information on environmental changes and sensing market needs. Collaborative research among companies will be effective for creating synergy. 


\section{Concluding remarks}

The primary focus of this study was on the survival of the Korean IoT-SMEs and the path of driving innovation for growth. Korean SMEs have been achieving innovation and growth in the traditional manufacturing sectors. However, as industries such as ICT, Big Data, IoT and Industry 4.0 have emerged recently, not only manufacturing SMEs but also IT-related companies are in the critical needs of adapting to changes. As such, the main motivation behind this study of dealing with the survival and innovative growth of IoT-SMEs lies in the fact that these companies are an important part of the infrastructure for building the ecosystem of the future industry.

In this study, we presented the factors for the IoT-SMEs facing the new environmental change to consider in making a strategic choice of the innovation-driving path type for their survival and sustainable growth. We found that the IoT has inherent disruptive and open innovation attributes. We also discovered that a successful IoT-SME has followed an innovation-driving and growth path consisting of self-evolution, aligned cooperation and their mix.

The IoT-SMEs in Korea are facing challenges in global market entry. The first obstacle is the lack of information to sense and judge the market situation. The lack of diverse information, which hinders decision making, makes it difficult for them to accommodate market needs. The second is the lack of capability to find a suitable BM. The IoT can lead to great results if synergy is created through close linkages with the intra or across the value chain companies. Those companies that produce chips, sensors, terminals, networks, equipment and platforms are playing the key roles in the Io $T$ value chain. It is important for companies to understand their role in the value chain and cooperate with the partners within and across the value chain. It is also critical for the companies without global market entry experience to create partnership and establish communication environment with experienced companies in the global market. This is the very sector where government support policy is needed in identifying environmental changes and global market trends and deriving a suitable BM for new markets. The support that enables creating more synergistic results does not have to be for companies with certain size, but for the companies within and across the value chain.

This study has its meaningful merit in that it suggested a new point of view to establish an innovation-driving path to enter overseas markets by linking Io $T$ innovation attributes. However, the limitation in this research is in using a single case study for the analysis to find an innovation-driving path. The future research need to replicate this study by investigating multiple cases of IoT-SMEs, for validating and enhancing this study findings. This study can be applied to large IoT companies to see whether there is a difference in innovation-driving path. Finally, it will be desirable to conduct studies for other emerging industries involving AI, big data, industry 4.0 and product-service convergence of XaaS (Everything as a Service).

\section{Notes}

1. Some perspectives in this study are based on "Research on the advancement of IoT related companies in foreign countries" of the Ministry of Science, ICT and Future Planning, 2014.11.30.

2. In WIPO's Global Innovation Index 2015, Korea ranked 14th in the world's competitiveness ranking and 2nd in Human Resources and Research, whereas Business sophistication ranked 30th and Creative Outputs 28th.

3. The Kauffman Foundation analyzed the percentage of OECD peers whose businesses started in 2006 in 2007 and 2009, respectively. 


\section{References}

Acs, Z.J. and Audretsch, D.B. (1990), Innovation and Small Firms, MIT Press, Cambridge, MA.

An, S.G. and Chun, H. (2015), Direction of Domestic and Foreign IoT Policy, KISTEP InI 13.

AnupSahoo (2016), Open Innovation in the Internet of Things, EFY Group.

Autio, E., Sapienza, H.J. and Almeida, J.G. (2000), "Effects of age at entry, knowledge intensity, and imitability on international growth", Academy of Management Journal, Vol. 43 No. 5, pp. 909-924.

Bernard, A.B. and Sjoholm, F. (2003), "Foreign owners and plant survival, NBER Work Pap Ser", Working Paper no. 10039, Cambridge, MA.

Beth, S. (2016), Five Disruptive Technologies to Track in 2017, Tech Forecast 2017, Computerworld.

Boon, C.F. and Looi, C.T. (2015), Io T Open Innovation Platform, Mosti.

Borg, E.A. (2009), "The marketing of innovations in high-technology companies: a network approach", European Journal of Marketing, Vol. 43 Nos 3/4, pp. 365-370.

Burgel, O. and Murray, G.C. (2000), "The international market entry choices of start-up companies in high-technology industries", Journal of International Marketing, Vol. 8 No. 2, pp. 33-62.

Carson, D. and Cromie, S. (1990), "Marketing planning in small enterprises: a model and some empirical evidence", Journal of Consumer Marketing, Vol. 7 No. 3, pp. 5-18.

Carson, D., Cromie, S., McGowan, P. and Hill, J. (1995), Marketing and Entrepreneurship in SMEs: An Innovative Approach, FT Prentice Hall, Hemel Hempstead.

Choi, S., Ryu, M., Chen, N. and Kim, J. (2014), "IoT platform and service trends", KICS, Vol. 31 No. 4, pp. 20-27.

Christensen, C.M., Anthony, S.D. and Roth, E.A. (2004), Seeing What's Next: Using the Theories of Innovation to Predict Industry Change, Havard Business School Press.

Chun, H.S. (2014), "Field application of IoT and future direction", KLID, Vol. 8, pp. 34-35.

CISCO (2014), "The internet of things”, IoT Networks, 2011.

Coviello, N.E. and McAuley, A. (1999), "Internationalisation and the smaller firm: a review of contemporary empirical research", Management International Review, Vol. 39 No. 3, pp. 223-256.

D'Aveni, R. (1994), Hypercompetition: Managing the Dynamics of Strategic Maneuvering, Free Press, New York, NY.

Deltatech Korea (2014), Study for Overseas Expansion of the Internet of Things.

Edwards, T., Delbridge, R. and Munday, M. (2005), "Understanding innovation in small and mediumsized enterprises: a process manifest", Technovation, Vol. 25, pp. 119-1120.

Egelhoff, W.G. and Haklisch, C.S. (1994), "Strategy, size of firm, and the use of technical alliances: an exploratory study", Journal of Engineering and Technology Management, Vol. 11 No. 2, pp. 117-148.

Enkel, E., Gassmann, O. and Chesbrough, H. (2009), "Open R\&D and open innovation: exploring the phenomenon", R\&D Management, Vol. 39, No. 4.

Esteve-Pérez, S., Máñez-Castillejo, J.A. and Sanchis-Llopis, J.A. (2007), "Does a 'survival-by-exporting' effect for SMEs exist?", Empirica, Vol. 35 No. 1, 81-104.

Femhaber, S.A., McDougall, P.P. and Oviatt, B.M. (2007), Exploring the Role of Industry.

Fillis, I. (2001), "Small firm internationalization: an investigative survey and future research directions", Management Decision, Vol. 19 No. 9, pp. 767-783.

Freeman, C. (1982), The Economics of Industrial Innovation, 2nd ed., Frances Pinter, London.

Frost \& Sullivan (2014), "Internet of Things (IoT) - disruptive opportunities in key sectors".

Fuller, P.B. (1994), “Assessing marketing in small and medium-sized enterprises”, European Journal of Marketing, Vol. 28 No. 12, pp. 34-49. 
Gartner (2013), Market Trends: TSPs Must Invest in the Rapidly Evolving Internet of Things Ecosystems Now.

Gemunden, H.G. and Heydebreck, P. (1995), "The influence of business strategies on technological network activities", Research Policy, Vol. 24 No. 6, pp. 831-849.

Gilmore, A., Carson, D. and Grant, K. (2001), "SME marketing in practice", Marketing Intelligence \& Planning, Vol. 19 No. 1, pp. 6-11.

Global Sensor Networks, Tata Consultancy Service, KISA (2012), Analysis of Market Policy Trends in Internet of Things.

Hatonen, J. and Ruokonen, M. (2010), "Revising marketing strategies for supplier selection criteria: small firm approach from the information and communications industry", Journal of Business \& Industrial Marketing, Vol. 25 No. 2, pp. 159-167.

Harris, R.I.D. (1988), "Technological change and regional development in the UK: evidence from the SPRU database on innovations", Regional Studies, Vol. 22, pp. 361-374.

Hausman, A. (2005), "Innovativeness among small businesses: theory and propositions for future research", Industrial Marketing Management, Vol. 34 No. 8, pp. 773-782.

Hill, J. (2001), “A multidimensional study of the key determinants of effective SME marketing activity: Part 1 and 2", International Journal of Entrepreneurial Behaviour \& Research, Vol. 7 Nos 5/6, pp. 171-235.

Hiromi Saito (2010), Choice of Independent R\&D and Open Innovation: Empirical Analysis Based on Questionnaire Data for Firms, Globelics.

Hoffman, K., Parejo, M., Bessant, J. and Perren, L. (1998), "Small firms R\&D, technology and innovation in the UK: a literature review", Technovation, Vol. 18 No. 1, pp. 39-45.

Hogarth, S.S., Watson, K. and Wilson, N. (1996), "Do small businesses have to practise marketing to survive and grow?”, Marketing Intelligence \& Planning, Vol. 14 No. 1, pp. 6-18.

IEEE (2015), "Towards a definition of the Internet of Things (IoT)".

ITU-T (2005), "The Internet of Things".

Jeong, J.-U. and Bae, Z. (1997), An Exploratory Study on the Change of the Technological Cooperation Pattern of Small and Medium Enterprises by Technology Development Stage, KOSIME.

Jeong, W.S., Kim, S.-H. and Min, K. (2013), “An analysis of the economic effects for the IoT industry", Journal of Korean Society for Internet Information, Vol. 14 No. 5, pp. 119-128.

Jones, O. and Tilley, F. (Eds) (2003), Competitive Advantage in SMEs: Organizing for Innovation and Change, Wiley, Chichester.

Kang, J. (2014), Factors Analysis Affecting Information Security in IOT Environment, KMIS.

Kang, B., Jeon, J. and Chung, S. (2013), A Policy Study for Activating Innovative Innovation of Small and Medium-sized Enterprises, KOTIS.

Kang, S., Kim, J. and Lee, J. (2014), The Journal of The Korean Institute of Communication Sciences, Vol. 31No. 4, NIA (National Information Society Agency), pp. 10-19.

Kanter, R.M. (1994), “Collaborative advantage: the art of alliances”, Harvard Business Review, Vol. 72, pp. 96-108.

Kapoor, R. and Adner, R. (2015), "Innovation ecosystems and the pace of substitution: re-examining technology S-Curves", Strategic Management Journal, Vol. 37 No. 4, pp. 625-648.

Karagozoglu, N. and Lindell, M. (1998), Internationalization of Small and Medium-Sized.

Kauffman Foundation (2015), Deconstructing Job Creation from Startups, Cross-Country Evidence on Start-up Dynamics, OECD Data Analysis.

Keeble, D. (1997), "Small firms, innovation and regional development in britain in the 1990s", Regional Studies, Vol. 31 No. 3, pp. 281-293. 
Kim, M. and Jung, W. (2013), Io T Related Value Chain and Market Component, KISDI, Chungcheongbuk-do.

Kim, M. and Lee, E. (2014), Io T Technology and Competitive Advantage, KISDI, Chungcheongbuk-do.

Kim, D., Kim, S., Ha, M. and Kim, T. (2011), Io T Technology and Future Development Direction, KICS.

Kim, S., Ahn, D.H., Song, J.G., Lee, J.W., Bee, Y.H. and Jun, J.Y. (2008), Open Innovation: Theory, Practices, and Policy Implications, Seoul, STEPI.

Knight, G.A. and Cavusgil, S.T. (2005), “A taxonomy of born-global firms”, Management International Review, Vol. 45 No. 3, pp. 15-35.

KOSTAT (2015), Enterprise Survival and Death Annual rates in 2014.

Kwon, J. and Kim, H. (2014), "The trends and cases of domestic conformity assessment on the IoT devices", The Magazine of the IEEE, Vol. 41 No. 8.

Kyllikki, T.-E., Pia, H. and Hannele, L. (2014), "Survival competence in Russian SMEs in a changing business environment", Journal of East-West Business, Vol. 20 No. 1.

Laforet, S. and Tann, J. (2006), "Innovative characteristics of small manufacturing firms", Journal of Small Business and Enterprise Development, Vol. 13 No. 3, pp. 363-380.

Laursen, K. and Salter, A.J. (2004), "Searching high and low: what type of firms use universities as a source of innovation?", Research Policy, Vol. 33 No. 8, pp. 1201-1215.

Lee, H.-G., Kim, M.-H. and Bang, H.-C. (2014), Io T Technology Trend and Development Direction, KIPS.

Lee, J., Hong, J. and Yoon, J. (2015), “An exploratory study of the early users of the internet of things using”, Journal of KSSSS, Vol. 30, pp. 89-107.

Lee, H., Kelley, D., Lee, J. and Lee, S. (2012), "SME survival: the impact of internationalization, technology resources, and alliances", Journal of Small Business Management, Vol. 50 No. 1, pp. 1-19.

Li, X. and Lu, Y. (2010), "Strategy development of SMEs in the Internet of Things era: case study on Chinese enterprises", Logistic and Innovation Management, University of GAVLE.

Ma, T. and Zhang, C. (2011), "On the disruptive potentials in Internet of things", 17th International Conference on Parallel and Distributed Systems (ICPADS), IEEE, Tainan.

Melitz, M.J. (2003), "The impact of trade in intra-industry reallocations and aggregate industry productivity", Econometrica, Vol. 71, pp. 1695-1725.

Moon, T. (2013), A Study of Priority Selection for applied target for Io T (Internet of Things) by Value Chain.

Nam, D. (2010), Development of Future Intelligence Communication and Future Service Model, RAPA.

O’Dwyer, M., Gilmore, A. and Carson D. (2009), "Innovative marketing in SMEs: a theoretical framework, European Business Review, Vol. 21 No. 6, pp. 504-515.

OECD (2005), "Oslo manual", Guidelines for Collecting and Interpreting Innovation Data, 3rd ed., OECD.

Oviatt, B.M. and McDougall, P.P. (1995), "Global start-ups: entrepreneurs on a worldwide stage”, The Academy of Management Executive, Vol. 9 No. 2, pp. 30-44.

Parkhe, A. (1993), "Strategic alliance structuring: a game theoretic and transaction cost examination of interfirm cooperation", Academy of Management Journal, Vol. 36 No. 4, pp. 794-829.

Pavitt, K. (1984), "Sectoral patterns of technical change: towards a taxonomy and a theory", Research Policy, Vol. 13, pp. 343-373.

Pavitt, K., Robinson, M. and Townsend, J. (1987), "The size distribution of innovating firms in UK: 1945-1983”, Journal of Industrial Economics, Vol. 35, pp. 297-316.

Prahalad, C.K. and Mashelkar, R.A. (2010), "Innovation's holy grail”, Harvard Business Review, Vol. 88 No. 7, pp. 132-141.

Rialp, A., Rialp, J. and Knight, G.A. (2005), The Phenomenon of Early Internationalizing Firms.

Rothwell, R. (1992), "Successful industrial innovation: critical success factors for the 1990s", R\&D Management, Vol. 22 No. 3, pp. 221-239. 
Rothwell, R. and Zegveld, W. (1982), Innovation and Small and Medium Sized Firm, Frances Pinter, London.

Salavou, H. (2004), "The concept of innovativeness: should we need to focus?", European Journal of Innovation Management, Vol. 7 No. 1, pp. 33-44.

Innovation strategies of the internet

Scott, M. and Bruce, R. (1987), "Five stages of growth in small business", Long Range Planning, Vol. 20 No. 3, pp. 45-52.

Simpson, M., Padmore, J., Taylor, N. and Frecknall-Hughes, J. (2006), "Marketing in small and Edium sized enterprises”, International Journal of Behaviour \& Research, Vol. 12 No. 6, pp. 361-387.

Smith, J.B., Mitchell, R.K., Seawright, K.W. and Morse, E.A. (2000), "Cross-cultural cognitions and the venture creating decision”, Academy of Management Journal, Vol. 43 No. 5, pp. 974-993.

Soete, L. (1979), "Firm size and innovative activity: the evidence reconsidered", European Economic Review, Vol. 12, pp. 319-340.

STRACORP (2013), Machina Research, p. 1.

Telecom Asia Vision (2016), Io T: Even More Disruptive Than You Think.

Tidd, J., Bessant, J. and Paviit, K. (2015), Managing Innovation, 3rd ed., John Wiley \& Sons, New York, NY.

Yli-Renko, H., Autio, E. and Tontti, V.X. (2002), "Social capital, knowledge, and the international growth of technology-based new firms", International Business Review, Vol. 11 No. 2, pp. 279-304.

WIPO (2015), The Global Innovation Index.

Zahra, S.A. (2005), "A theory of international new ventures: a decade of research", Journal of International Business Studies, Vol. 36 No. 1, pp. 20-28.

Zahra, S.A. and George, G. (2002), "International entrepreneurship: the current status of the field and future research agenda", Strategic Entrepreneurship: Creating a New Mindset, pp. 255-288.

Zahra, S.A., Matherne, B.P. and Carleton, J.M. (2003), "Technological resource leveraging and the internationalisation of new ventures", Journal of International Entrepreneurship, Vol. 1 No. 2, pp. 163-186.

Zain, M. and Ng, S.I. (2006), "The impacts of network relationships on SMEs' internationalization process", Thunderbird International Business Review, Vol. 48 No. 2, pp. 183-205.

\section{Further reading}

KOITA (2014), Technology Management.

Gassmann, O. and Enkel, E. (2004), "Towards a Theory of Open Innovation: Three Core Process Archetypes", R\&D Management Conference (RADMA), Lisabon, pp. 1-18.

MSIFP, Ministry of Science, ICT and Future Planning (2014), Study for Overseas Expansion of the Internet of Things.

\section{Website}

http://electronicsofthings.com/expert-opinion/open-innovation-internet-things/

\section{Corresponding author}

Dong-Il Shin can be contacted at: sdi@csdicon.net

For instructions on how to order reprints of this article, please visit our website:

www.emeraldgrouppublishing.com/licensing/reprints.htm

Or contact us for further details: permissions@emeraldinsight.com 